\title{
Managing Resistance to Change in Medical Education
}

\author{
Alam Sher Malik ${ }^{1}$ and Rukhsana Hussain Malik ${ }^{2}$ \\ ${ }^{1}$ Department of Paediatrics, International Medical School, Management and Science University, Shah Alam, Malaysia \\ ${ }^{2}$ Consultant Medical Educationist, Shah Alam, Malaysia
}

"Just as a continual stream of new technologies and discoveries brings advancements to patient care, so do innovations in teaching methods and curricular designs constantly evolve to provide students with cutting-edge curricula". - Bland et al . ${ }^{1}$ However, changes in medical education are not accepted as straightforwardly as changes in areas related to patient care. Interestingly, the resistance in medical education is selective; maximumly directed to the teaching and learning methods (pedagogy) and minimal to the content (e.g. modern insights into pathophysiology) or tools of teaching (e.g. PowerPoint).

Resistance is a natural phenomenon and a positive reaction to change. It is also a protective response as all the changes may not be positive. Resistance should not be misunderstood as outright disapproval or rejection of change; rather it should be interpreted as a conditional acceptance. ${ }^{2}$ It serves as a qualitative check for ensuring the change to achieve the highest possible standards within the limits of available resources. Resistance also protects against complacency and overconfidence that may develop in the change-team. ${ }^{2}$ When it comes to implementation of change, several factors such as environment, cost, use of technology and the pace of implementation need to be considered carefully. ${ }^{3} \mathrm{~A}$ number of reasons for resistance to change in medical education have been cited in the literature such as: strong existing traditions or paradigms; failure to perceive the need for the change; lack of patience among change workers; misinformation; lack of self-criticism and sense of insecurity among academic staff members; questionable credibility of the change leaders and conspiracy theories. $^{4-6}$

There are some suggestions stated in the literature for managing the resistance to change in medical education. The first is to establish the need (to solve a problem; to achieve better outcomes) for the change; ${ }^{1}$ Get support of influential people (both among administration and academics) to implement the change; ${ }^{3}$ Design the change (solution to the problem/innovation/proposal) with the help of experts and relevant people; Publicise the proposed change; Get support and agreement of all the stakeholders to implement the change; Implement the change and use all the means available to overcome the hurdles and difficulties in implementation; ${ }^{1}$ and finally modify the change, if needed for proper implementation. ${ }^{2}$

Correspondence to: Dr. Alam Sher Malik, Department of Paediatrics, International Medical School, Management and Science University, Shah Alam, Malaysia

E-mail: alamshermalik@hotmail.com

Received: August 04, 2021; Revised: August 31, 2021; Accepted: September 17, 2021

DOI: https://doi.org/10.29271/jcpsp.2021.10.1141
Recently, MedEd Webinar Series, ${ }^{7}$ a voluntary international organisation for promotion of medical education with a membership of more than a thousand medical educationists and teachers over 14 countries, conducted an online discussion among its associates. The discussion point was, "As medical teachers, we are always delighted to get the latest edition of a book (up-to-date content) and we have moved happily from blackboard-and-chalk to the PowerPoint presentations (teaching tools). However, some of us strongly resist the innovations in the curriculum such as problem-based learning curriculum and new teaching/learning methods such as PBL or TBL sessions, etc. What do you think is the most likely reason for this anomaly?" This dialogue was open for two days and more than 50 members, predominantly from Pakistan and India (two countries where largely hybrid PBL curriculum is being followed), participated actively with great enthusiasm. A number of issues were raised and suggestions were made to tacklethese issues.

During this discussion, lack of trust between medical teachers and medical educationists emerged as a major reason for resistance to the implementation of PBL (PBL - both as a curriculum and a teaching method) - a reason scarcely mentioned in the literature. ${ }^{4-6}$ Senior medical teachers saw the medical educationists as inexperienced junior staff members, who have just graduated from medical schools, received some training in medical education and started criticising seasoned academicians - some of them their own teachers. Some of these senior academicians did not recognise medical education as a speciality-discipline. On the other hand, the medical educationists saw them as old teachers, who are stubborn and do not want to move out of their comfort zones and change their ways as they are scared of losing authority and power. The other issue raised by the senior academicians was that the young medical educationists have just theoretical knowledge and try to impress by using difficult terms and jargons. They do not have any teaching and assessment experience and do not know what is actually happening on the ground.

The administrators of the medical institutions can play a vital role to manage this debilitating mistrust between medical teachers and medical educationists. Some suggestions were brought up during the said discussion, which need to be considered for implementing the change in medical education. ${ }^{7}$ Create an environment of respect for each other, not just verbally, but by observable behaviour and actions. Recognise each other's strengths and status. The seniors should be given due respect, and juniors should listened to respectfully. Discussions and arguments should be based on the evidence and logic rather than on 
personal positions or status. Senior academicians need to recognise the capabilities of students of modern times, and different attributes required by the doctors of the $21^{\text {st }}$ century. The young medical educationists should not limit themselves to only office work, rather should be enthusiastically involved in teaching and learning activities for medical students; for example, facilitating PBL sessions, contributing in teaching sessions by teaching the non-technical skills or transferable skills. They should also actively contribute in the student assessment activities; for example, developing and vetting of questions, invigilation during written and clinical examinations. It should be realised that change occurs gradually over a long period of time and needs patience and perseverance. The credit of success and responsibility of failure should be shared by all. Like students, academic staff members are also fast and slow learners; and thus the staff development activities may need to be repeated many times.

We hope that these recommendations will help to minimise the resistance to change in medical education globally, in general; and in the sub-continent, in particular.

\section{REFERENCES}

1. Bland CJ, Starnaman S, Wersal L, Rosenberg LM, Zonia S, Henry R. Curricular change in medical schools: How to
Succeed. Acad Med 2000; 75(6):575-94. doi: 10.1097/ 00001888-200006000-00006.

2. Gale R, Grant J. AMEE medical education guide No. 10: Managing change in a medical context: Guidelines for action. Med Teach 1997; 19(4):239-49. doi:10.3109/01421 599709034200.

3. Tekian A, Harden RM, Cook DA, Steinert Y, Hunt D, Norcini J. Managing the tension: From innovation to application in health professions education. Med Teach 2020; 42(3):333-9. doi:10.1080/0142159X.2019.1687871.

4. Thompson G. Faculty recalcitrance about bibliographic instruction. In: Hardesty L, Hastreiter J, Henderson D, Eds. Bibliographic instruction in practice; A tribute to the legacy of Evan Ira Farber. Ann Arbor; Michigan: Pierian Press; 1993: p.103-5.

5. Lane IF. Change in higher education: understanding and responding to individual and organizational resistance. J Vet Med Educ 2007; 34(2):85-92. doi: 10.3138/jvme. 34.2.85.

6. Chandler N. Braced for turbulence: Understanding and managing resistance to change in the higher education sector. Management 2013; 3(5): 243-51 doi: 10.5923/ j.mm.20130305.01

7. Malik RH. MedEd Webinar 16. PBL: Process, Roles and Responsibilities. http://www.youtube.com/watch?v=aN1 EYEnOvBQ\&t=17s\&ab_channel=MedEd. 